Journal of Mathematics and Statistics 3 (2): 54-57, 2007

ISSN 1549-3644

(C) 2007 Science Publications

\title{
Fixed Points of Non-expansive Operators on Weakly Cauchy Normed Spaces
}

\author{
Sahar Mohamed Ali \\ Department of Mathematics, Faculty of Science, Ain Shams University, Cairo, Egypt
}

\begin{abstract}
We proved the existence of fixed points of non-expansive operators defined on weakly Cauchy spaces in which parallelogram law holds, the given normed space is not necessarily be uniformly convex Banach space or Hilbert space, we reduced the completeness and the uniform convexity assumptions which imposed on the given normed space.
\end{abstract}

Key words: Fixed points, non-expensive operators, normed spaces, convexity

\section{INTRODUCTION}

Let $\mathrm{C}$ be a bounded closed convex subset of a Banach space $\mathrm{X}$, and let $\mathrm{T}$ be a non-expansive mapping from $\mathrm{C}$ into itself, as we know, the fixed point set $F(T):=\{x \in C: T(x)=x\}$ may be empty. The quest for geometric conditions on $\mathrm{C}$ which will guarantee the existence of at least one fixed point for which nonexpansive self mapping of $\mathrm{C}$ has leds to an extensive fixed point theory for non-expansive mappings. Many results have been given independently by Browder ${ }^{[1]}$, Gohde $^{[2]}$ and $\operatorname{Kirk}^{[3]}$, they showed that

Theorem $1^{[2]}$ : Let $X$ be a uniformly convex Banach space, $\mathrm{C}$ be a nonempty bounded closed convex subset of $\mathrm{X}$ and $\mathrm{T}$ be a non-expansive operator from $\mathrm{C}$ into itself. Then $\mathrm{T}$ has a fixed point.

$\operatorname{In}^{[4]}$, we used the concept of weakly Cauchy normed space to prove the existence of a fixed point of a contraction mapping on a given weakly Cauchy normed space and we will use this result to prove the existence of fixed points of a non-expansive operator on that space.

Theorem $2^{[4]}$ : Let $X$ be a weakly Cauchy normed space, $\mathrm{C}$ be a closed convex subset of $\mathrm{X}$ and $\mathrm{T}$ be a contraction mapping from $\mathrm{C}$ into $\mathrm{C}$. Then $\mathrm{T}$ has a unique fixed point $\mathrm{y} \in \mathrm{C}$. Moreover $\left\{\mathrm{T}^{\mathrm{n}}(\mathrm{x})\right\}_{\mathrm{n}} \in \in_{\mathrm{N}}$ is strongly convergent to $\mathrm{y}$ for every $\mathrm{x} \in \mathrm{C}, \lim _{\mathrm{n} \rightarrow \infty}$ $\mathrm{T}^{\mathrm{n}}(\mathrm{x})=\mathrm{y}$ for every $\mathrm{x} \in \mathrm{C}$.

We remark that, if $y$ is a fixed point of a contraction operator, then the inequality

$\left\|\mathrm{T}^{\mathrm{n}}(\mathrm{x})-\mathrm{T}(\mathrm{y})\right\|=\left\|\mathrm{T}^{\mathrm{n}}(\mathrm{x})-\mathrm{T}^{\mathrm{n}}(\mathrm{y})\right\| \leq \mathrm{r}^{\mathrm{n}} \quad\|\mathrm{x}-\mathrm{y}\|$ for ever $\mathrm{x} \in \mathrm{C}$ insures that the sequence of iterates $\left.\mathrm{T}^{\mathrm{n}}(\mathrm{x})\right\}_{\mathrm{n}} \in \in_{\mathrm{N}}$ is strongly convergent to $\mathrm{y}$ for every $\mathrm{x} \in \mathrm{C}$.
In this study, we will use theorem (3) below to prove the existence of a come point of descending sequence of bounded closed convex subsets of a weakly Cauchy normed space in which the parallelogram law holds, in this case we reduced the completeness and uniform convexity imposed on the given normed space.

Theorem $3^{[5]}$ : Let $\mathrm{X}$ be a weakly Cauchy normed space in which the parallelogram law holds. Then every nonempty closed convex subset $\mathrm{C}$ of $\mathrm{X}$ is Chebyshev. Equivalently the metric projection $\mathrm{P}_{\mathrm{C}}$ exists on every nonempty closed convex subset of $\mathrm{X}$, for every $\mathrm{x} \in \mathrm{X}$ there exists a unique element $\mathrm{P}_{\mathrm{C}}(\mathrm{x})=\mathrm{y} \in \mathrm{C}$ called the best approximation element of $\mathrm{x}$ in $\mathrm{C}$ such that $\|x-y\|=\operatorname{dist}(x, C):=\inf \{\|x-z\|: \quad z \in C\}$.

We mention here that the last result used the concept of weakly Cauchy normed spaces to prove the existence of the best approximation elements of a convex closed subsets in normed spaces not necessarily be reflexive Banach space or Hilbert space in general.

Notations and basic definition ${ }^{[6]}$ : Let $\mathrm{X}$ be a normed space and $\mathrm{f}$ be a function $\mathrm{f}$ from $\mathrm{X}$ into $[0, \infty)$. Then

1. $\mathrm{f}$ is said to be lower semicontinuous if and only if for any real number $\alpha$, the set $\{\mathrm{x} \in \mathrm{X}: \mathrm{f}(\mathrm{x}) \leq \alpha\}$ is closed convex subset of $\mathrm{X}$.

2. $f$ is said to be convex if and only if for any $\mathrm{x}, \quad \mathrm{y} \in \mathrm{X}$ and $\mathrm{t} \in[0,, 1], \quad \mathrm{f}(\mathrm{t} \mathrm{x}+(1-\mathrm{t}) \mathrm{y}) \leq \mathrm{t}$ $f(x)+(1-t) f(y)$.

Definition ${ }^{[4,5]}$ : A normed space $X$ is said to be weakly Cauchy normed space if and only if every Cauchy sequence in $\mathrm{X}$ is weakly convergent to an element $\mathrm{X}$ in $\mathrm{X}$.

Corresponding Author: Sahar Mohamed Ali, Department of Mathematics, Faculty of Science, Ain Shams University, Cairo, Egypt 
Definition ${ }^{[6]}$ : Let $\mathrm{X}$ be a normed space, $\mathrm{T}$ be a mapping from $X$ into itself. Then

1. $\mathrm{T}$ is said to be Lipschitzian if and only if there exists a non-negative real number $r$ such that $\| \mathrm{T}(\mathrm{x})$ $\mathrm{T}(\mathrm{y})\|\leq \mathrm{r}\| \mathrm{x}-\mathrm{y} \|$ for every $\mathrm{x}, \mathrm{y} \in \mathrm{X}$.

2. $\quad \mathrm{T}$ is said to be contraction if and only if there is a non-negative real number $\mathrm{r}<1$ with the property that $\|T(x)-T(y)\| \leq r\|x-y\|$ for every $x, y \in X$.

3. $\mathrm{T}$ is said to be non-expansive if and only if $\| \mathrm{T}(\mathrm{x})$ $\mathrm{T}(\mathrm{y})\|\leq\| \mathrm{x}-\mathrm{y} \|$ for every $\mathrm{x}, \mathrm{y} \in \mathrm{X}$.

A point $\mathrm{y} \in \mathrm{X}$ is said to be fixed point with respect to the operator $\mathrm{T}$ if and only if $\mathrm{T}(\mathrm{y})=\mathrm{y}, \mathrm{F}(\mathrm{T})$ will denote the set of all fixed points of $\mathrm{T}$.

The non-expansive operators may not have fixed point even on uniformly convex (not bounded) Banach spaces in general.

Depending only on the parallelogram law, we have the following lemma.

Lemma $1^{[6]}$ : Let $X$ be a normed space in which parallelogram law holds, $\mathrm{C}$ be a closed convex subset of $\mathrm{X}$. If $\mathrm{T}$ is a non-expansive operator on $\mathrm{C}$ into $\mathrm{C}$, then $\mathrm{F}(\mathrm{T})$ is closed convex subset of $\mathrm{X}$.

We proved the following:

Lemma 2: Let X be a weakly Cauchy normed space in which the parallelogram law holds, $\mathrm{C}$ be a closed convex subset of $\mathrm{X}$. If $\mathrm{T}$ is a non-expansive operator on $\mathrm{C}$ into $\mathrm{C}$ and the set of fixed point $\mathrm{F}(\mathrm{T})$ is nonempty, then $F(T)$ is Chebyshev subset of $X$.

Proof: Using theorem (3) and lemma (1), we get the proof.

We have the following main proposition.

Proposition 1: Let $X$ be weakly Cauchy normed space in which parallelogram law holds, if $\left\{\mathrm{C}_{\mathrm{n}}\right\}_{\mathrm{n}} \in \in_{\mathrm{N}}$ is descending sequence of closed bounded convex subsets of X, then the intersection $\bigcap_{n=1}^{\infty} C_{n} \neq \Phi$ is not empty.

Proof: Let $\mathrm{z}$ be a point in $\mathrm{X}$ not in $\mathrm{C}_{1}$, using theorem (3), there is a unique sequence $\left\{x_{n}\right\}_{n=1}^{\infty}, x_{n} \in C_{n}$ such that $\left\|z-x_{n}\right\|=\operatorname{dist}\left(z, C_{n}\right):=\inf \left\{\|y-z\|: y \in C_{n}\right\}$ for every $n \in N$, Let $\left\{r_{n}\right\}_{n=1}^{\infty}$ be a sequence of real numbers defined by $r_{n}:=\left\|z-x_{n}\right\|$, since $\left\{\mathrm{C}_{\mathrm{n}}\right\}_{\mathrm{n}} \in \in_{\mathrm{N}}$ is descending, $\left\{r_{n}\right\}_{n=1}^{\infty}$ is increasing which is bounded above by $\operatorname{Diam}\left(\{z\} \cup C_{1}\right)$, hence $\left\{r_{n}\right\}_{n=1}^{\infty}$ is convergent to some real number $\mathrm{r}, \mathrm{r}=\lim _{n \longrightarrow \infty} r_{n}$, we claim that the sequence $\left\{x_{n}\right\}_{n=1}^{\infty}$ is a Cauchy sequence in $\mathrm{X}$, to prove this claim, let $n, m \in N$ and $n>m$, using the parallelogram law, we have

$$
\begin{aligned}
& r_{m}^{2} \leq\left\|z-\frac{x_{n}+x_{m}}{2}\right\|^{2}=2\left\|\frac{z-x_{n}}{2}\right\|^{2}+2\left\|\frac{z-x_{m}}{2}\right\|^{2}-\left\|\frac{x_{m}-x_{n}}{2}\right\|^{2} \\
& =\frac{1}{2}\left\|z-x_{n}\right\|^{2}+\frac{1}{2}\left\|z-x_{m}\right\|^{2}-\frac{1}{4}\left\|x_{m}-x_{n}\right\|^{2} \\
& =\frac{1}{2} r_{n}{ }^{2}+\frac{1}{2} r_{m}{ }^{2}-\frac{1}{4}\left\|x_{m}-x_{n}\right\|^{2}
\end{aligned}
$$

Taking the limit as $m \longrightarrow \infty$, we see that $r^{2} \leq \frac{1}{2} r^{2}+\frac{1}{2} r^{2}-\frac{1}{4} \lim _{m \longrightarrow \infty}\left\|x_{m}-x_{m}\right\|^{2}, \quad 0 \leq-\frac{1}{4} \lim _{m \longrightarrow \infty}\left\|x_{m}-x_{m}\right\|^{2}$, this is a contradiction unless $\lim _{m \longrightarrow \infty}\left\|x_{m}-x_{m}\right\|=0$. Therefore $\left\{x_{n}\right\}_{n=1}^{\infty}$ is a Cauchy sequence in $\mathrm{X}$, since $\mathrm{X}$ is weakly Cauchy normed space, $\left\{x_{n}\right\}_{n=1}^{\infty}$ is weakly convergent to some point $\mathrm{x}$ in $\mathrm{X}$, for every $\mathrm{n}$, the sequence $x_{n}, x_{n+1}, x_{n+2}, \ldots$ is weakly convergent to $\mathrm{x}$, since $C_{n}$ is closed convex, $C_{n}$ is containing all its weak limits as well as all its strong limits, $x \in C_{n}$ for every $\mathrm{n} \in \mathrm{N}$, thus $\mathrm{x} \in \bigcap_{n=1}^{\infty} C_{n}$ and $\bigcap_{n=1}^{\infty} C_{n} \neq \Phi$.

Corollary 1: Let $X$ be weakly Cauchy normed space in which parallelogram law holds, $\mathrm{C}$ be a closed convex subset of $\mathrm{X}$, and $f: C \longrightarrow[0, \infty)$ be a convex lower semicontinuous function from $\mathrm{C}$ into $[0, \infty)$ with the property that $\mathrm{f}(\mathrm{x}) \longrightarrow \infty$ as $\|\mathrm{x}\| \longrightarrow \infty$. Then $\mathrm{f}$ attains its infimum on $X$, if in addition $f\left(\frac{x+y}{2}\right)<\operatorname{Max}\{f(x), f(y)\}$ at exactly one point.

, then $\mathrm{f}$ attains its minimum

Proof: Let $\left\{\lambda_{n}\right\}_{n=1}^{\infty}$ be a converging to zero sequence of real numbers, apply Proposition (1) with $C_{n}=\left\{x \in C: f(x)<\inf _{x \in C} f(x)+\lambda_{n}\right\}$, there exists $\mathrm{x}_{0}$ in C such that $f\left(x_{0}\right)<\inf _{x \in C} f(x)+\lambda_{n} \forall n \in N$, $\mathrm{f}$ attains its minimum at $\mathrm{x}_{0}$, if $\mathrm{f}$ attains its minimum at two different elements $\mathrm{x}$ and $\mathrm{y}$, since $(\mathrm{x}+\mathrm{y}) / 2$ is an element of $\mathrm{C}$, the next strict inequality gives a contradiction

$$
f\left(\frac{x+y}{2}\right)<\operatorname{Max}\{f(x), f(y)\}=\mathrm{f}(\mathrm{x})=\mathrm{f}(\mathrm{y})=\inf _{x \in C} f(x) .
$$


The following Theorem is my Main purpose to prove.

Theorem 4: Let $X$ be a weakly Cauchy normed space, $\mathrm{C}$ be a nonempty bounded closed convex subset of $\mathrm{X}$, and $\mathrm{T}$ be a non-expansive operator from $\mathrm{C}$ into itself. Then $\inf \{\|x-T(x)\|: x \in C\}=0$. Moreover, if the parallelogram law holds in the given weakly Cauchy normed space $\mathrm{X}$, then $\mathrm{T}$ has fixed point. Moreover if $\mathrm{C}_{1}$ $[0,1]$ is the set of all nonnegative sequence of real numbers $\left\{r_{n}\right\}_{n=1}^{\infty}, \quad 0 \leq r_{n}<1$ and $r_{n} \stackrel{n \longrightarrow \infty}{\longrightarrow} 1$, then $\mathrm{CxC}_{1}[0,1] \subset \mathrm{F}(\mathrm{T})$.

Proof: Fix a point $\mathrm{y}_{0} \in \mathrm{C}$, let $\left\{r_{n}\right\}_{n=1}^{\infty}$ be a sequence of non negative real numbers $0 \leq r_{n}<1$ and $r_{n} \stackrel{n \longrightarrow \infty}{\longrightarrow} 1$. Define corresponding sequence of contraction operators as follows:

$T_{n}(x):=\left(1-r_{n}\right) y_{0}+r_{n} T(x)$.

In fact,

$\left\|T_{n}(x)-T_{n}(z)\right\|=r_{n}\|T(x)-T(z)\| \leq r_{n}\|x-z\|$ for $\quad$ every $\quad x, z \in C$.

Using theorem (2), for each $n, T_{n}$ has a unique fixed point $\mathrm{x}_{\mathrm{n}} \in \mathrm{C}, \mathrm{T}_{\mathrm{n}}\left(\mathrm{x}_{\mathrm{n}}\right)=\mathrm{x}_{\mathrm{n}}$. Hence a sequence $\left\{x_{n}\right\}_{n=1}^{\infty} \subset C_{\text {such that }} x_{n}:=\left(1-r_{n}\right) y_{0}+r_{n} T\left(x_{n}\right)$.

We have, $\left\|x_{n}-T\left(x_{n}\right)\right\|=\left(1-r_{n}\right)\left\|y_{0}-T\left(x_{n}\right)\right\| \leq\left(1-r_{n}\right) \operatorname{Diam}(C)$.

Taking the limit as $\mathrm{n}$ tends to $\infty$, $\left\|x_{n}-T\left(x_{n}\right)\right\| \stackrel{n \longrightarrow \infty}{\longrightarrow} 0$. This limit insures that $\inf \{\|x-T(x)\|: x \in C\}=0$

The

function $\phi_{\left\{x_{n}\right\}_{n=1}^{\infty}}: C \longrightarrow[0, \infty)$

defined

$$
\phi_{\left\{x_{n}\right\}_{n=1}^{\infty}}(x):=\limsup _{n \longrightarrow \infty}\left\|x_{n}-x\right\|
$$

by $\quad n \longrightarrow \infty$ is a convex lower semicontiuous function satisfying the properties of Corollary (1), hence there is exactly one element $\mathrm{z}$ in $\mathrm{X}$ such that

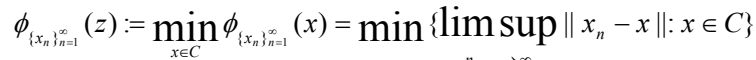

$$
\begin{aligned}
& \text { since } \\
& \left\|x_{n}-T(z)\right\| \leq\left\|x_{n}-T\left(x_{n}\right)\right\|+\left\|T\left(x_{n}\right)-(z)\right\| \\
& \leq\left\|x_{n}-T\left(x_{n}\right)\right\|+\left\|x_{n}-z\right\|
\end{aligned}
$$

we have

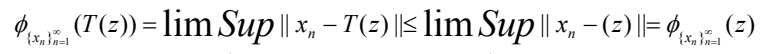

This proved that $\phi_{\left\{x_{n}\right\}_{n=1}^{\infty}}$ is also attained its infimum at
$\mathrm{T}(\mathrm{z})$, since the minimum is unique, $\mathrm{T}(\mathrm{z})=\mathrm{z}$, and $\mathrm{z}$ is a fixed point of $\mathrm{T}$.

We have the following remarks.

Remarks 1: Let $\mathrm{X}$ be a metric space, $\mathrm{T}$ be Lipschitzian mapping on $\mathrm{X}$, and $\left\{x_{n}\right\}_{n=1}^{\infty} \subset X$ be a sequence in $\mathrm{X}$ such that $d\left(x_{n}, T\left(x_{n}\right)\right) \stackrel{n \longrightarrow \infty}{\longrightarrow} 0 . \quad$ If $\quad\left\{x_{n}\right\}_{n=1}^{\infty}$ is strongly convergent to a point $\mathrm{y}$ of $\mathrm{X}$, then $\mathrm{y}$ is a fixed point of T. In fact, let y be the limit point of $\left\{x_{n}\right\}_{n=1}^{\infty}$, we have the following convergent,

$d(y, T(y)) \leq d\left(x_{n}, y\right)+d\left(x_{n}, T\left(x_{n}\right)\right)+d\left(T\left(x_{n}\right), T(y)\right)$

$$
\begin{aligned}
& \leq d\left(x_{n}, y\right)+d\left(x_{n}, T\left(x_{n}\right)\right)+r d\left(x_{n}, y\right) \\
& \leq(1+r) d\left(x_{n}, y\right)+d\left(x_{n}, T\left(x_{n}\right)\right) \stackrel{n \longrightarrow \infty}{\longrightarrow} 0 .
\end{aligned}
$$

This proved that $\mathrm{T}(\mathrm{y})=\mathrm{y}$.

Remark 2: Since every non-expansive operator is Lipschitzian with $0<\mathrm{r}<1$, we see that remark (1) is true for the non-expansive operators.

Remark 3: Let $X$ be metric space, $T$ be Lipschitzian mapping from $X$ into $X, x$ be a fixed point of $T$, and $\left\{x_{n}\right\}_{n=1}^{\infty}$ be a sequence in $\mathrm{X}$, if $\left\{x_{n}\right\}_{n=1}^{\infty}$ converges strongly to $\mathrm{x}$, then $d\left(x_{n}, T\left(x_{n}\right)\right) \stackrel{n \longrightarrow \infty}{\longrightarrow} 0$, if $\mathrm{r}$ not equal one the converse is true. In fact, let $\left\{x_{n}\right\}_{n=1}^{\infty}$ converges strongly to $\mathrm{x}$. Then

$d\left(x_{n}, T\left(x_{n}\right)\right) \leq d\left(x_{n}, x\right)+d\left(T\left(x_{n}\right), x\right)$

$$
=d\left(x_{n}, x\right)+d\left(T\left(x_{n}\right), T(x)\right)
$$

$$
\leq d\left(x_{n}, x\right)+r d\left(x_{n}, x\right)=(1+r) d\left(x_{n}, x\right) \stackrel{n \longrightarrow \infty}{\longrightarrow} 0 .
$$

This proved that $d\left(x_{n}, T\left(x_{n}\right)\right) \stackrel{n \longrightarrow \infty}{\longrightarrow} 0$.

Conversely, let $\mathrm{r}$ be not equal one and $d\left(x_{n}, T\left(x_{n}\right)\right) \stackrel{n \longrightarrow \infty}{\longrightarrow} 0$, we have

$$
\begin{aligned}
d\left(x_{n}, x\right) & \leq d\left(x_{n}, T\left(x_{n}\right)\right)+d\left(T\left(x_{n}\right), x\right) \\
& =d\left(x_{n}, T\left(x_{n}\right)\right)+d\left(T\left(x_{n}\right), T(x)\right) \\
& \leq d\left(x_{n}, T\left(x_{n}\right)\right)+r d\left(x_{n}, x\right) .
\end{aligned}
$$

The following convergent is proved that $\left\{x_{n}\right\}_{n=1}^{\infty}$ converges strongly to $\mathrm{x}$.

$d\left(x_{n}, x\right) \leq \frac{d\left(x_{n}, T\left(x_{n}\right)\right)}{(1-r)} \stackrel{n \longrightarrow \infty}{\longrightarrow} 0$ 
Remark 4: Since a contraction mapping is $r$ contraction with $0<r<1$, If $X$ is complete metric space, $\mathrm{T}$ is contraction mapping from $\mathrm{X}$ into $\mathrm{X},\left\{x_{n}\right\}_{n=1}^{\infty} \subset X$, then $\left\{x_{n}\right\}_{n=1}^{\infty}$ converges strongly to the unique fixed point of $\mathrm{T}$ if and only if $d\left(x_{n}, T\left(x_{n}\right)\right) \stackrel{n \longrightarrow \infty}{\longrightarrow} 0$.

Remark 5: If $\mathrm{T}$ is Lipchitzian, $\mathrm{r}$ not equal one, and $\mathrm{T}$ has a fixed point $\mathrm{x}$, then there is a nontrivial sequence $\left\{x_{n}\right\}_{n=1}^{\infty}$ in C converges strongly to the fixed point of T. In fact, let $\mathrm{T}$ be $\mathrm{r}$-contraction, $\mathrm{r}$ not equal one, and $\mathrm{T}$ has a fixed point $\mathrm{x}$. The sequence given in (2) is not only Cauchy but also strongly convergent to the fixed point of T. In fact. To show that $\left\{x_{n}\right\}_{n=1}^{\infty} \subset C$ is Cauchy sequence, we have

$$
\begin{aligned}
& \begin{aligned}
\left\|x_{n}-x_{m}\right\| & =\left\|r_{n}\left\{T\left(x_{n}\right)-T\left(x_{m}\right)\right\}+\left(r_{n}-r_{m}\right) T\left(x_{m}\right)+\left(r_{m}-r_{n}\right) y_{0}\right\| \\
& \leq r_{n}\left\|T\left(x_{n}\right)-T\left(x_{m}\right)\right\|+\mid r_{n}-r_{m}\left\|T\left(x_{m}\right)-y_{0}\right\| \\
& \leq r_{n} r\left\|x_{n}-x_{m}\right\|+\left|r_{n}-r_{m}\right| \operatorname{Diam}(C),
\end{aligned} \\
& \text { thus, }\left(1-r_{n} r\right)\left\|x_{n}-x_{m}\right\| \leq\left|r_{n}-r_{m}\right| \operatorname{Diam}(C),
\end{aligned}
$$

since $\left\{r_{n}\right\}_{n=1}^{\infty}$ is Cauchy, we see that, $\left\|x_{n}-x_{m}\right\| \leq \frac{\left|r_{n}-r_{m}\right| \operatorname{Diam}(C)}{\left(1-r_{n} r\right)} \stackrel{n, m \longrightarrow \infty}{\longrightarrow} 0$.

Since $\mathrm{X}$ is weakly Cauchy, the sequence $\left\{x_{n}\right\}_{n=1}^{\infty}$ is weakly convergent, the weak convergent of the sequence is clearly strong convergent.

Remark 6: If $T$ is non-expansive, $C$ is a bounded closed convex subset of a weakly Cauchy normed space $\mathrm{X},\left\{r_{n}\right\}_{n=1}^{\infty}$ is a sequence of non negative real numbers such that $0 \leq r_{n}<1$, and $r_{n} \stackrel{n \longrightarrow \infty}{\longrightarrow} t<1$ then the sequence given by $x_{n}:=\left(1-r_{n}\right) y_{0}+r_{n} T\left(x_{n}\right)$ is Cauchy sequence, but not necessarily $d\left(x_{n}, T\left(x_{n}\right)\right) \stackrel{n \longrightarrow \infty}{\longrightarrow} 0$. In fact, we have

$$
\left\|x_{n}-x_{m}\right\|=\left\|r_{n}\left\{T\left(x_{n}\right)-T\left(x_{m}\right)\right\}+\left(r_{n}-r_{m}\right) T\left(x_{m}\right)+\left(r_{m}-r_{n}\right) y_{0}\right\|
$$$$
\leq r_{n}\left\|T\left(x_{n}\right)-T\left(x_{m}\right)\right\|+\mid r_{n}-r_{m}\left\|T\left(x_{m}\right)+y_{0}\right\|
$$$$
\leq r_{n}|| x_{n}-x_{m} \|+\left|r_{n}-r_{m}\right| \operatorname{Diam}(C),
$$

thus, $\left(1-r_{n}\right)|| x_{n}-x_{m}|| \leq\left|r_{n}-r_{m}\right| \operatorname{Diam}(C)$,

since $\left\{r_{n}\right\}_{n=1}^{\infty}$ is Cauchy, we see that,

$\| x_{n}-x_{m}|| \leq \frac{\left|r_{n}-r_{m}\right| \operatorname{Diam}(C)}{\left(1-r_{n}\right)} \stackrel{n, m \longrightarrow \infty}{\longrightarrow} 0$.

\section{REFERENCES}

1. Browder, F.E., 1965. Non-expansive nonlinear operators in Banach space. Proc. Nat. Acad. Sci. U.S.A., 54: 1041-1044.

2. Gohde, D., 1965. Zum Prinzip der Kontrativan Abbildung. Math. Nachr., 30: 251-258.

3. Kirk, W.A., 1965. A fixed point theorem for mappings which do not increase distances. Amer. Math. Monthly, 72: 1004-1006.

4. Ali, S.M., 2006. Reduced assumption in the Banach contraction principle. J. Math. Stat., pp: 343-345.

5. El-Shobaky, E.M., S.M. Ali and W. Takahashi, 2001. On the projection constant problems and the existence of the metric projections in normed spaces. Abstr. Appl. Anal., 6: 401-410.

6. Wataru, T., 2000. Nonlinear Functional Analysis, Fixed Point Theory and its Applications. Yokohama Publishers, Yokohama. 